\title{
Conflict adaptation in schizophrenia: reviewing past and previewing future efforts
}

\section{Elger Abrahamse, Marit Ruitenberg, Wout Duthoo, Bernard Sabbe, Manuel Morrens \& Jean-Philippe van Dijck}

To cite this article: Elger Abrahamse, Marit Ruitenberg, Wout Duthoo, Bernard Sabbe, Manuel Morrens \& Jean-Philippe van Dijck (2016): Conflict adaptation in schizophrenia: reviewing past and previewing future efforts, Cognitive Neuropsychiatry, DOI: 10.1080/13546805.2016.1167679

To link to this article: $\mathrm{http}: / / d x . d o i . o r g / 10.1080 / 13546805.2016 .1167679$

册Published online: 21 Apr 2016.

Submit your article to this journal $\asymp$

Џ Article views: 18

Q View related articles $₫$

View Crossmark data $\nearrow$ 


\title{
Conflict adaptation in schizophrenia: reviewing past and previewing future efforts
}

\author{
Elger Abrahamse ${ }^{a}$, Marit Ruitenberg ${ }^{a, b}$, Wout Duthoo ${ }^{a}$, Bernard Sabbe ${ }^{c, d}$, \\ Manuel Morrens ${ }^{\mathrm{c}, \mathrm{d}, \mathrm{e}}$ and Jean-Philippe van Dijck ${ }^{\mathrm{a}, \mathrm{c}}$
}

${ }^{a}$ Faculty of Psychology and Educational Sciences, Department of Experimental Psychology, Ghent University,

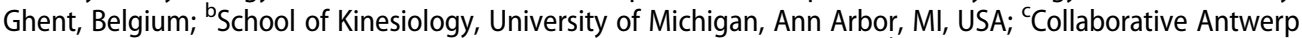
Psychiatric Research Institute, University of Antwerp, Antwerp, Belgium; 'University Department of

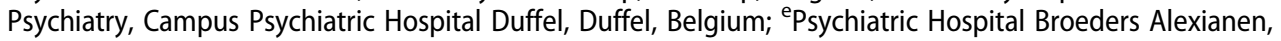
Boechout, Belgium

\begin{abstract}
Introduction: Cognitive control impairments have been suggested to be a critical component in the overall cognitive deficits observed in patients diagnosed with schizophrenia. Here, we zoom in on a specific function of cognitive control, conflict adaptation. Abnormal neural activity patterns have been observed for patients diagnosed with schizophrenia in core conflict adaptation areas such as anterior cingulate cortex and prefrontal cortex. On the one hand, this strongly indicates that conflict adaptation is affected. On the other hand, however, outcomes at the behavioural level are needed to create a window into a precise interpretation of this abnormal neural activity.

Methods. We present a narrative review of behavioural work within the context of conflict adaptation in schizophrenia, focusing on various major conflict adaptation markers: congruency sequence effects, proportion congruency effects, and post-error and postconflict slowing. The review emphasises both methodological and theoretical aspects that are relevant to the understanding of conflict adaptation in schizophrenia.

Results. Based on the currently available set of behavioural studies on conflict adaptation, no clear-cut answer can be provided as to the precise conflict adaptation processes that are impaired (and to what extent) in schizophrenia populations.

Conclusions. Future work is needed in state-of-the-art designs in order to reach better insight into the specifics of conflict adaptation impairments associated with schizophrenia.
\end{abstract}

\section{ARTICLE HISTORY}

Received 31 March 2015

Accepted 12 March 2016

\section{KEYWORDS}

Cognitive control; conflict adaptation; schizophrenia; congruency sequence effect; proportion congruency effect

Besides the well-established positive and negative symptoms, patients suffering from schizophrenia also struggle with diminished cognitive abilities. The most parsimonious account of this overall cognitive dysfunction may centre on deficits in cognitive control functions (Barch \& Ceaser, 2012; Lesh, Niendam, Minzenberg, \& Carter, 2011). Indeed, patients diagnosed with schizophrenia often suffer from enhanced vulnerability to distraction, show difficulties 
in monitoring their own behaviour (e.g., Frith \& Done, 1989), are impaired in the initiation and maintenance of goal-directed behaviour (Morrens, Hulstijn, \& Sabbe, 2007; Morrens, Hulstijn, Lewi, \& Sabbe, 2008), and fail to adjust their responses based on feedback or contextual changes (Elliott, McKenna, Robbins, \& Sahakian, 1995). This indicates that cognitive control is an important research topic, not only to understand general dysfunction in schizophrenia but also with an eye on improving real-world functioning because cognitive deficits are, more than other symptom domains, predictive for the social and functional outcome of patients diagnosed with schizophrenia (Bowie \& Harvey, 2005; Green et al., 2004). As cognitive control is a heterogeneous concept, at times it is worthwhile to zoom in on specific functions. In the current review paper, we highlight a specific function of cognitive control that has been coined conflict adaptation: Do patients diagnosed with schizophrenia functionally adjust their information processing after experiencing cognitive conflict?

One dominant framework from which to understand the management of cognitive conflict is the conflict monitoring theory of Botvinick, Braver, Barch, Carter, and Cohen (2001) - a framework that has also been dominant in previous work on schizophrenia and cognitive control (Barch, 2005). Here, we adhere to this framework, even though we realise that various other frameworks on cognitive control exist that are equally worthwhile to consider in the challenge of understanding cognitive control impairments in schizophrenia (e.g., Alexander \& Brown, 2011; Blais, Robidoux, Risko, \& Besner, 2007; Botvinick, 2007; Jiang, Heller, \& Egner, 2014; Silvetti, Seurinck, \& Verguts, 2011; Verguts \& Notebaert, 2009; Verguts, Vassena, \& Silvetti, 2015). The approach of the current paper will be to focus both on theoretical and methodological aspects of previous work in this domain in order to explore how conflict adaptation is impaired in schizophrenia. We will first discuss various markers of conflict adaptation that have been at the core of the conflict monitoring theory. Next, we will provide a brief review on the work that has explored these markers in patients diagnosed with schizophrenia. Finally, we will identify potential problems with the methodologies used in previous work, discuss how these problems may be overcome, and identify various avenues that could strengthen the theoretical foundation in this domain. Overall, we will conclude that much future work is needed to obtain a clear view on the specifics of conflict adaptation in schizophrenia.

\section{Markers of conflict adaptation}

Cognitive control denotes brain processes that allow maintaining goal-directed behaviour in the face of challenging situations (e.g., distractions, habitual but incorrect responses). For example, consider how you will be extra careful (i.e., enhanced control) in the canteen after a wet floor almost made you slip - with your plate full of food still in your hands. In the lab, cognitive control processes have been studied extensively using - among others - so-called conflict tasks. As an example let us take the Stroop task. In this task, a participant is presented with a colour-word (e.g., RED or GREEN) depicted in a specific ink-colour (e.g., green or red ink). When asked to name the ink-colour of each item, the irrelevant colour-word information has been shown to systematically impact performance: performance improves when colour-word and ink-colour match (e.g., the word RED in red ink) as compared to when they mismatch (e.g., the word RED in green ink). This so-called congruency effect can be taken as a marker of selective attention (or, conversely, distractibility) processes, reflecting how much the brain invests 
in focusing on the most relevant information. Research has confirmed that the Stroop congruency effect (both in terms of response times and error percentages) is systematically increased in schizophrenia patients as compared to healthy controls (Westerhausen, Kompus, \& Hugdahl, 2011), possibly indicating that patients diagnosed with schizophrenia suffer from deficient cognitive control mechanisms (but see Westerhausen, Kompus, \& Hugdahl, 2013).

Although immediate performance may benefit from high attentional focus, being at a constant "high" is very costly in terms of effort (Kool, McGuire, Rosen, \& Botvinick, 2010; Schouppe, De Houwer, Ridderinkhof, \& Notebaert, 2012; Shenhav, Botvinick, \& Cohen, 2013). Moreover, it may prevent useful explorative behaviour (e.g., Cools, 2015) and thereby the pickup of new contingencies in the environment (e.g., Bocanegra \& Hommel, 2014). Therefore, the brain is believed to constantly adjust selective attention to the demands that it is faced with: selective attention is enhanced at times of high conflict (such as when two mutually exclusive actions are simultaneously activated), whereas selective attention relaxes when conflict resolves (e.g., Egner \& Hirsch, 2005). This so-called conflict adaptation - the neural processes related to the resolution of conflicting activations in the brain - has become a major topic of cognitive control research over the last decades.

Conflict adaptation research is based on various behavioural markers that can be robustly reproduced in the lab. First, adaptation may occur on a trial-by-trial basis, as has been demonstrated by effects of the previous on the current trial. Specifically, in conflict tasks like the Stroop, larger congruency effects are typically observed after a congruent than after an incongruent trial (i.e., congruency sequence effect). This is interpreted in terms of a relatively increased attentional focus on the relevant information after incongruent trials - or, conversely, a relatively decreased focus after congruent trials. Second, adaptation may also follow from list-wide manipulations with respect to the frequency of occurrence of (in)congruent trials. That is, congruency effects decrease when increasing the overall proportion of incongruent Stroop trials. This proportion congruency effect is (partly) interpreted in terms of a general increase of focus on the relevant portion of information when conflict is frequently experienced within a certain (list) context (Bugg \& Crump, 2012; Bugg, McDaniel, Scullin, \& Braver, 2011).

The congruency sequence and proportion congruency effects are markers that relate to adaptation by adjusting the attentional settings. Yet, the brain may also adapt by adjusting the speed-accuracy trade off. Hence, the brain can "slow down" performance in response to conflicting situations so as to increase control. The idea is that accuracy will increase by providing additional time to accrue evidence for the most appropriate response. This slowing can be observed both after conflicting events that are eventually correctly solved (i.e., post-conflict slowing; Verguts, Notebaert, Kunde, \& Wühr, 2011 ${ }^{1}$ ), and after full-blown errors (i.e., post-error slowing; Notebaert et al., 2009). Not much research has directly focused on post-conflict slowing, its underlying mechanism, or its relationship to post-error slowing. Because of their conceptual overlap and the fact that some major theories (e.g., Botvinick et al., 2001) assume shared underlying mechanisms between post-error and post-conflict slowing, we have opted to discuss them together throughout the current paper. We acknowledge, however, that there are also indications for non-overlapping mechanisms (e.g., Forster \& Cho, 2014). 
The congruency sequence effect, the proportion congruency effect, and post-error and post-conflict slowing have inspired ample research over the last decades in both healthy and patient populations.

\section{Conflict adaptation and schizophrenia}

There are strong justifications for a broad and systematic exploration of conflict adaptation markers in schizophrenia. Most importantly, patients diagnosed with schizophrenia show structural and functional abnormalities in brain areas tightly related to conflict adaptation. Specifically, ample studies have shown abnormal activity in the anterior cingulate cortex (ACC; e.g., Carter, Mintun, Nichols, \& Cohen, 1997; Kerns et al., 2005; Minzenberg, Gomes, Yoon, Swaab, \& Carter, 2014) and dorsolateral prefrontal cortex (DLPFC) (e.g., Lesh et al., 2011,2013). Even though the precise roles that these areas fulfil are still being debated, major models assume the ACC to detect co-activation of incompatible responses (with errors being an extreme case of conflict; Botvinick et al., 2001) or to signal unexpected outcomes more generally (Alexander \& Brown, 2011; Holroyd \& Coles, 2002; Silvetti et al., 2011). Prefrontal areas may be involved in control processes to resolve discrepancies or conflict (Botvinick et al., 2001).

In addition to earlier work on action monitoring (Frith \& Done, 1989) and daily life experiences, observations at the neural level thus suggest that schizophrenia involves impaired adaptation to conflicting situations. Crucially, despite the clear link of ACC and DLPFC to adaptation in healthy controls and a clear difference in neural activity between patients diagnosed with schizophrenia and healthy controls, outcomes at the behavioural level should ultimately serve the purpose of creating a window into the interpretation of the (deviating) neural activity in schizophrenia. That is, without clear insight into the various behavioural markers of conflict adaptation it remains unknown where exactly are the impairments situated (e.g., is there a problem with attentional modulation, adjusting the speed-accuracy balance, or both?). Here, we briefly outline the behavioural work in this domain.

Table 1 shows schizophrenia studies that have moved beyond overall congruency effects into the domain of conflict adaptation. It becomes immediately clear that posterror slowing has been explored most extensively. Whether such slowing occurs in patients diagnosed with schizophrenia in a similar manner as in healthy controls is still an issue of debate, though, with some studies showing reliable post-error slowing in patients diagnosed with schizophrenia (Alain, McNeely, He, Christensen, \& West, 2002; Houthoofd et al., 2013; Mathalon et al., 2002; Polli et al., 2006) and others not (Becerril, Repovs, \& Barch, 2011; Carter, MacDonald, Ross, \& Stenger, 2001; Kerns et al., 2005). Yet, together with the studies of Becerril and Barch (2013) and Minzenberg et al. (2014) showing similar post-conflict slowing between patients diagnosed with schizophrenia and healthy controls, it may be tentatively concluded that slowing in schizophrenia reliably occurs in response to cognitive conflict.

A much smaller set of studies explored the congruency sequence effect (Kerns et al., 2005; McNeely, West, Christensen, \& Alain, 2003; Völter et al., 2012). Here, again, the data are not unequivocal, with McNeely et al. (2003) showing similar congruency sequence effects in patients diagnosed with schizophrenia and healthy controls, whereas Kerns et al. (2005) observed an absence of the congruency sequence effect in 
Table 1. An overview of studies investigating the congruency sequence effect, the proportion congruency effect, post-conflict slowing or post-error slowing in patients diagnosed with schizophrenia.

\begin{tabular}{|c|c|c|c|c|c|}
\hline Marker of adaptation & Study & Population & Task & Results & $\begin{array}{l}\text { Potential problems with design and/or data } \\
\text { analysis }\end{array}$ \\
\hline \multirow[t]{3}{*}{$\begin{array}{l}\text { Congruency sequence } \\
\text { effect }\end{array}$} & Kerns et al. (2005) & $\begin{array}{l}\text { Patients diagnosed with schizophrenia } \\
\quad(n=13) \text { versus healthy controls } \\
(n=13)\end{array}$ & Stroop & $\begin{array}{l}\text { No congruency sequence effect in } \\
\text { patients diagnosed with } \\
\text { schizophrenia after controlling for } \\
\text { stimulus repetitions }\end{array}$ & $\begin{array}{l}\text { - Response repetition confound } \\
\text { - S-R contingency confound } \\
\text { - Stimulus repetitions and S-R } \\
\text { contingencies experienced during task } \\
\text { execution may block conflict adaptation } \\
\text { (see Bugg, 2014) }\end{array}$ \\
\hline & McNeely et al. (2003) & $\begin{array}{l}\text { Patients diagnosed with schizophrenia } \\
(n=12) \text { or schizoaffective disorder } \\
(n=1) \text { versus healthy controls } \\
(n=13)\end{array}$ & Stroop & $\begin{array}{l}\text { Similar congruency sequence effects } \\
\text { between patients diagnosed with } \\
\text { schizophrenia and healthy controls }\end{array}$ & $\begin{array}{l}\text { - Stimulus/response repetition confounds } \\
\text { - S-R contingency confound } \\
\text { - Stimulus/response repetitions } \\
\text { experienced during task execution may } \\
\text { block conflict adaptation (see Bugg, 2014) }\end{array}$ \\
\hline & $\begin{array}{l}\text { Völter et al. (2012) } \\
(N=106)\end{array}$ & Healthy population & Stroop & $\begin{array}{l}\text { Negative correlation between } \\
\text { congruency sequence effect and SPQ } \\
\text { results }\end{array}$ & $\begin{array}{l}\text { - Stimulus/response repetition confounds } \\
\text { - S-R contingency confound } \\
\text { - Stimulus/response repetitions and/or S-R } \\
\text { contingencies experienced during task } \\
\text { execution may block conflict adaptation } \\
\text { (see Bugg, 2014) }\end{array}$ \\
\hline $\begin{array}{l}\text { Proportion effect } \\
\text { (different proportions } \\
\text { of neutral trials) }\end{array}$ & Henik et al. (2002) & $\begin{array}{l}\text { Patients diagnosed with schizophrenia } \\
\qquad \begin{array}{l}(n=11) \text { versus healthy controls } \\
(n=16)\end{array}\end{array}$ & Stroop & $\begin{array}{l}\text { Both patients diagnosed with } \\
\text { schizophrenia and healthy controls } \\
\text { show the proportion effect* }\end{array}$ & $\begin{array}{l}\text { - Stimulus/response repetition confounds } \\
\text { - List-shifting effect (which may differ } \\
\text { between groups) } \\
\text { - S-R contingency confound }\end{array}$ \\
\hline Post-conflict slowing & $\begin{array}{l}\text { Becerril and Barch } \\
\text { (2013) }\end{array}$ & $\begin{array}{l}\text { Patients diagnosed with schizophrenia } \\
\qquad \begin{array}{l}(n=35) \text { versus healthy controls } \\
(n=37)\end{array}\end{array}$ & Change-signal & $\begin{array}{l}\text { No differences between patients } \\
\text { diagnosed with schizophrenia and } \\
\text { healthy controls }\end{array}$ & - No post-conflict accuracy increase \\
\hline
\end{tabular}


Task

Minzenberg et al. Patients diagnosed with schizophrenia Stroop

(2014)

Post-error slowing

Alain et al. (2002) Patients diagnosed with schizophrenia Stroop

Patients diagnosed with schizophrent versus healthy controls $(n=12)$

Bates, Liddle, Kiehl, Patients diagnosed with schizophrenia Go/no-go and Ngan (2004) $\quad(n=9)$ versus healthy controls $(n=9)$

Becerril and Barch Patients diagnosed with schizophrenia Change-signal (2013) $(n=38)$ versus healthy controls

$$
(n=39)
$$

Botvinick et al. Patients diagnosed with schizophrenia Continuous

$(n=17)$ versus healthy controls$$
(n=16)
$$$$
\text { AX }
$$

Houthoofd et al. Patients diagnosed with schizophrenia Eriksen flanker $(n=12)$ versus healthy controls $(n=12)$

Kerns et al. (2005) Patients diagnosed with schizophrenia Stroop $(n=13)$ versus healthy controls $(n=13)$

Laurens, Ngan Bates, Kiehl, and Liddle (2003)

Mathalon et al.

Patients diagnosed with schizophrenia Go/no-go $(n=10)$ versus healthy controls

$$
(n=16)
$$

Patients diagnosed with schizophrenia Picture-word $(n=18)$ versus healthy controls verification

$$
(n=18)
$$

McNeely et al. (2003) Patients diagnosed with schizophrenia Stroop $(n=12)$ or schizoaffective disorde $(n=1)$ versus healthy controls $(n=13)$
Potential problems with design and/or data analysis

No differences between patients

- No post-conflict accuracy increase

diagnosed with schizophrenia and

healthy controls

Though reliable in both groups, post- - No data on post-error accuracy

error slowing was larger in healthy - No optimal baseline using pre-error trials controls than patients

No post-error slowing for both patients - No data on post-error accuracy diagnosed with schizophrenia and - No optimal baseline using pre-error trials healthy controls

No post-error slowing for both patients - No post-error increase of accuracy diagnosed with schizophrenia and - No optimal baseline using pre-error trials healthy controls

Post-error slowing larger in healthy controls than patients diagnosed

- No data on post-error accuracy with schizophrenia

Reliable and similar post-error slowing - No post-error increase of accuracy between healthy controls and patients diagnosed with schizophrenia

Post-error slowing only in healthy controls

- No data on post-error accuracy

- No optimal baseline using pre-error trials

Reliable post-error slowing in patients - No data on post-error accuracy diagnosed with schizophrenia

- No optimal baseline using pre-error trials

Reliable and similar post-error slowing - No data on post-error accuracy in both groups $\quad$ - No optimal baseline using pre-error trials

Similar post-error slowing in both groups
- Stimulus/response repetition confounds

- S-R contingency confound

- Stimulus/response repetitions experienced during task execution may block conflict adaptation (see Bugg, 2014) 


\begin{tabular}{|c|c|c|c|c|c|}
\hline Marker of adaptation & Study & Population & Task & Results & $\begin{array}{c}\text { Potential problems with design and/or data } \\
\text { analysis }\end{array}$ \\
\hline & $\begin{array}{l}\text { Minzenberg et al. } \\
\text { (2014) }\end{array}$ & $\begin{array}{l}\text { Patients diagnosed with schizophrenia } \\
(n=73) \text { versus healthy controls } \\
(n=54)\end{array}$ & Stroop & $\begin{array}{l}\text { Post-error slowing reliable and similar } \\
\text { to healthy controls }\end{array}$ & $\begin{array}{l}\text { - Reliable drop in post-error accuracy in } \\
\text { patients diagnosed with schizophrenia } \\
\text { - No optimal baseline using pre-error trials }\end{array}$ \\
\hline
\end{tabular}

Núñez Castellar et al. Patients diagnosed with schizophrenia Four-choice RT No post-error slowing in both healthy - No data on post-error accuracy

(2012) $\quad(n=17)$ versus healthy controls

$$
\begin{aligned}
& (n=17) \text { vers } \\
& (n=15)
\end{aligned}
$$

Perez et al. (2012) Patients diagnosed with schizophrenia Picture-word $(n=88)$ versus healthy controls verification $(n=135)$ erification

Polli et al. (2006) Patients diagnosed with schizophrenia Anti-saccade $(n=21)$ versus healthy controls

$$
(n=14)
$$

Polli et al. (2008) Patients diagnosed with schizophrenia Anti-saccade $(n=18)$ versus healthy controls $(n=15)$ controls and schizophrenic patients - No optimal baseline using pre-error trials

Reliable slowing in patients diagnosed - No post-error accuracy data

with schizophrenia, and similar to - No optimal baseline using pre-error trials healthy controls

Similar and reliable post-error slowing - No post-error accuracy data - No optimal baseline using pre-error trials

Trend towards post-error slowing in - No post-error accuracy data

both groups $\quad$ - No optimal baseline using pre-error trials

Note: SPQ, Schizotypal Personality Questionnaire; S-R, stimulus-response.

*Despite both groups showing the proportion effect, Henik et al.'s (2002) report on more specific proportion-driven differences between patients diagnosed with schizophrenia and healthy controls.

**In the paper it is actually not fully clear if pre-error trials or trials after a correct response served as a baseline. 
schizophrenia. The study by Völter et al. (2012) - showing a correlation between the size of the congruency sequence effect and an individuals scores on the Schizotypal Personality Questionnaire - corroborates the latter study, but stronger empirical back-up is desired. Finally, to our knowledge, only one study explored the effect of manipulating proportions of neutral trials - which may have a similar impact as manipulating overall proportion congruency (Tzelgov, Henik, \& Berger, 1992) - showing that patients diagnosed with schizophrenia show this effect similar to healthy controls (Henik et al., 2002).

It is clear that - maybe aside from work on post-error slowing - the empirical database on conflict adaptation in schizophrenia is currently too small to allow definite conclusions. Moreover, besides being too few in number, we will argue later that most of the studies in Table 1 suffer from methodological and/or data-analytical flaws.

\section{Conflict adaptation: where to go from here?}

For a correct understanding of conflict adaptation it is crucial to use state-of-the-art designs because various confounds have been identified - and designs have been modified to deal with these confounds. Yet, as becomes clear from Table 1, almost all of the available studies on conflict adaptation in schizophrenia have used confounded designs. Here, we outline the various issues and indicate how these may be overcome.

\section{Congruency sequence effect}

Despite its central role in conflict adaptation research, the typical data pattern underlying the congruency sequence effect has been explained by various alternative episodic memory accounts that question the role of attentional modulation - a core feature of conflict adaptation - in bringing about the effect. These alternative views have been at the heart of heated debate over recent years (for reviews see Braem, Abrahamse, Duthoo, \& Notebaert, 2014; Duthoo, Abrahamse, Braem, Böhler, \& Notebaert, 2014a; Schmidt, 2013). For example, feature integration accounts state that the data pattern underlying the congruency sequence effect can be explained by the costs of partial repetitions of stimulus and/or response features - which are more frequent for congruency alternations than congruency repetitions (Mayr, 2004; Hommel, Proctor, \& Vu, 2004). The contingency learning account adds that most observations of congruency sequence effects are confounded by stimulus-response (S-R) contingency learning processes (Mordkoff, 2012; Schmidt, 2013; Schmidt \& De Houwer, 2011). Specifically, when using all possible incongruent items in a typical Stroop design, congruent trials contain higher contingency between the word feature and the correct response than incongruent trials, and current trial and previous trial contingency have been shown to interact to produce a similar data pattern as the congruency sequence effect (Schmidt \& De Houwer, 2011).

In response to these alternative accounts, a series of methodological improvements have been put forward that exclude episodic memory confounds a priori (see later). Yet, research on cognitive control in schizophrenia has not yet had the chance to apply these more optimal task designs. As a consequence, the few relevant studies on the congruency sequence effect in schizophrenia (Henik et al., 2002; Kerns et al., 2005; McNeely et al., 2003; Völter et al., 2012) are difficult to interpret - especially since it has been reported that episodic memory is impaired in patients diagnosed with 
schizophrenia (Barch \& Ceaser, 2012; but see Baving, Wagner, Cohen, \& Rockstroh, 2001). It is also not necessarily sufficient to re-analyse existing data sets on the overall congruency effect - of which there are many (for reviews see Westerhausen et al., 2011, 2013) - and explore previous trial effects in them. These studies, too, are plagued by episodic confounds, and conflict adaptation is at its strongest in designs that do not allow for these episodic effects to affect performance during the experiment (Bugg, 2014). Hence, efforts are needed in this domain that adopt stimulus designs that are freed of various episodic confounds a priori. Let us briefly consider some possibilities along this line.

One can adopt the strategy of employing two 2-stimuli congruency tasks with separate S-R mappings that alternate on a trial-by-trial basis. As such, features never repeat over successive trials, and contingencies are kept equal across the experiment. In a Stroop task, for example, this can be achieved by alternating between two colour pairs and, thus, two sets of congruent and incongruent trials (Jiménez \& Méndez, 2013; Weissman, Jiang, \& Egner, 2014). A similar strategy has been applied to the flanker task (Kim \& Cho, 2014) and prime-target congruency task (Schmidt \& Weissman, 2014). In these unconfounded designs the congruency sequence effect was still observed. Corroborating these findings, Duthoo, Abrahamse, Braem, Böhler, and Notebaert (2014b) employed a vocal six-colour Stroop task in which colour and word never repeated across two consecutive trials and each word was equally often paired with its congruent colour as with one of the five remaining incongruent colours. In this way, colour-word contingencies were also equated between congruent and incongruent trials, whereas the ratio of congruent/ incongruent trials was kept at 50\% (see Mordkoff, 2012). Moreover, a six-letter manual flanker task was constructed in a similar vein, whereas a picture-word Stroop interference task with 120 unique congruent and incongruent picture-word combinations was administered to further minimise the contribution of memory biases. Across all three tasks, reliable congruency sequence effects were observed. This type of design may be used in schizophrenia research to obtain better insight in trial-by-trial adaptation to conflict levels.

\section{Proportion congruency effects}

Proportion congruency effects come in various versions. As mentioned earlier, the typical proportion congruency manipulation is list-wide, such that overall proportion congruency is either high or low in a specific trial list. The finding of smaller congruency effects with higher proportions of incongruent trials is often understood to (at least partly) reflect a sustained type of attentional modulation towards relevant (or away from irrelevant) information (Bugg et al., 2011). Besides the list-wide impact of proportion congruency, however, more context-based effects have also been reported (i.e., context-specific proportion congruency effects). Most importantly, it has been shown that different proportion congruency effects can be acquired for different screen locations (location-specific proportion congruency effect) or item sets (item-specific proportion congruency effect). For example, when the proportion congruency is high for one screen location on which items can be presented, but low for another, larger and smaller congruency effects, respectively, develop for these locations. Importantly, since location is presented in random order, these effects indicate a reflexive, on-the-fly implementation of enhanced cognitive control within the ongoing trial. ${ }^{2}$ 
On-the-fly conflict adaptation is extremely important for cognitive functioning and behaviour in times where unexpected challenges are encountered from our environment, but it has not yet been studied much in patients diagnosed with schizophrenia. It critically relies on rapid steering by "external cues" (such as item or item location) and thus requires specific binding processes between features of the environment and specific control settings. Since patients diagnosed with schizophrenia have been shown to be impaired in binding items to a location (e.g., Burglen et al., 2004), we would tentatively predict that these patients would develop the location-specific proportion congruency effect to a much smaller extent than is the case for healthy controls. Hence, patients diagnosed with schizophrenia may experience difficulty with on-the-fly adaptation as they fail to appropriately use the cues that in healthy subjects develop on the basis of binding processes. This type of hypothesis needs to be explored while preventing confounds as much as possible.

For the various types of proportion congruency effects, similar episodic memory confounds have been identified to those discussed earlier for the congruency sequence effect. This mainly relates to $\mathrm{S}-\mathrm{R}$ contingencies, as participants can learn to predict the response that is most frequently associated with a given stimulus. That is, in the high and low proportion congruent conditions, responses to congruent and incongruent trials will be faster than usual, respectively, because they are related to higher S-R contingency (Schmidt, 2013; Schmidt \& Besner, 2008). This produces the typical proportion congruency data pattern without any need for attentional modulation to be assumed. Like in abovementioned congruency sequence effect studies it will be critical to find a solution to this contingency confound. Along this line it may be worthwhile to consider determining the conflict adaptation effect for a separate set of proportion- and contingency-unbiased (i.e., diagnostic) stimuli that are mixed with the manipulated stimuli (e.g., Bugg et al., 2011; Crump \& Milliken, 2009). Another issue to consider is the observation of order effects in within-subject designs of high versus low proportion congruency trial lists. Specifically, Abrahamse, Duthoo, Notebaert, and Risko (2013) showed that starting with a low proportion congruency trial list that is then followed by a high proportion congruency trial list has different overall impact on the congruency effect than the reversed order. If this so-called list-shifting effect would differ between (patients diagnosed with schizophrenia versus healthy control) populations, this would hinder appropriate interpretation.

Overall, even though the proportion congruency effect is hardly explored in schizophrenia research, it constitutes an important marker of conflict adaptation and we therefore vow for more extensive research along this line while considering the S-R contingency issue.

\section{Slowing to improve accuracy}

Generally, we believe that most (if not all) of the work on slowing in Table 1 is critically flawed by ignoring the flip side of the speed-accuracy coin - that is, when slowing occurs, what happens to accuracy? Without a corresponding increase in post-conflict or posterror accuracy it seems difficult to defend slowing as a mechanism of adaptation. Indeed, at least numerically, decreases in accuracy are often observed after conflict or an error (e.g., Becerril \& Barch, 2013; Minzenberget al., 2014). It has to be noted that this is a delicate issue; for example, Jentzsch and Dudschig (2009) showed that 
post-error accuracy is critically depended on how much time is given after an error (e.g., by the response-stimulus interval). Yet, based on current empirical work there is little to say about the functionality of slowing of response times, leaving open the possibility that slowing is driven by non-functional mechanisms such as, for example, an orienting response (Notebaertet al., 2009). Indeed, schizophrenia has been related to more substantial distraction by novel stimuli (Braff, 1993; Grillon, Courchesne, Ameli, Geyer, \& Braff, 1990) and impaired reorientation of processing resources to salient novel stimuli (Braff, 1993; Gray, 1995; Grillon et al., 1990; Kapur, 2003).

In addition to enhanced consideration of post-conflict and post-error accuracy, it is also important to prevent the confound of performance improvements that occur over the course of an experiment: Most errors (and thus post-error trials) occur early on in the experiment when participants are still slow at responding, compared to post-correct trials that mostly occur later in the experiment when performance is generally faster. Dutilh et al. (2012) proposed a simple solution to this problem, as one can just compare data of post-error trials with those of pre-error trials (as opposed to postcorrect trials), so that the effect of possible performance improvements over time is eliminated. A few studies in Table 1 have adopted this approach (e.g., Carter et al., 2001), but it is recommended for future research to widely do so.

\section{Conflict as an affective event}

Before closing the paper we would like to briefly outline recent ideas on the critical feature of (response) conflict that is driving adaptations. Specifically, recent studies suggest that conflict is an aversive signal (Botvinick, 2007; Dreisbach \& Fischer, 2012; Fritz \& Dreisbach, 2013; Schouppe et al., 2015), and it has been suggested that it is mainly this aversive feature that motivates adaptation (Dreisbach \& Fischer, 2015). For now this remains an assumption, as the aversive quality of conflict may also be a mere byproduct of a reduced fluency of processing - and thus be only correlated with adaptation. However, it is of interest for the current paper because people diagnosed with schizophrenia are known to exhibit maladaptive (expression and) processing of emotional valence (O'Driscoll, Laing, \& Mason, 2014), and this may thus provide a theoretical foundation to impaired conflict adaptation in this population. As such, clear empirical indices of conflict adaptation in people diagnosed with schizophrenia may be paralleled by - and correlated with - direct tests of the processing of emotional valence. This would greatly increase our understanding of conflict adaptation, both in the case of people diagnosed with schizophrenia and in more general terms.

\section{Outlook}

Overall, despite clear theoretical and practical relevance, in our opinion there are very few clearly interpretable studies on behavioural adaptation to conflict in the literature on schizophrenia populations. As such, the abnormal patterns of neural activity - that clearly suggest impairments in adaptation - are not directly corroborated at the behavioural level. This hinders a clear overview on global cognitive control functioning, as well as conclusions with respect to specific subcomponents, in this population. Here we argue in favour of more substantial exploration in this domain on the basis of a broad 
set of behavioural markers, and the use of state-of-the-art designs (which are developing rapidly) that prevent (extensive) clinical studies to turn out inconclusive. Moreover, there are probably further critical aspects that should be considered into detail to speed up the progress in understanding cognitive control functioning in schizophrenia, such as patient characteristics and medication use. Only from there we may obtain a clear insight into the precise meaning of abnormal neural activity in conflict adaptation areas in the brain as is observed in this population.

\section{Disclosure statement}

No potential conflict of interest was reported by the authors.

\section{Funding}

E. A. was supported by Research Foundation - Flanders [grant number 12C4715N]. M. R. was supported by the Research Foundation - Flanders as a Pegasus Marie Curie Fellow [grant number $1262214 \mathrm{~N}]$. M. M. received financial support for research activities and scientific presentations by Johnson \& Johnson, AstraZeneca, Lundbeck, and Bristol-Myers Squibb.

\section{Notes}

1. The authors show that post-conflict slowing may not be consistently observed because it is typically masked by the processing of the irrelevant stimulus dimension.

2. Reminiscent of this type of on-the-fly adaptation by proportion congruency, the congruency sequence effect at least partly reflects reflexive control (e.g., Egner, Ely, \& Grinband, 2010); this is supported, for example, by the observation that within-trial adjustments can be observed on the basis of current trial congruency (Scherbaum, Fischer, Dshemuchadse, \& Goschke, 2011). Some studies, however, have indicated a more sustained component as well (e.g., Duthoo, Abrahamse, Braem, \& Notebaert, 2014). The link between the reflexive component of trial-by-trial conflict adaptation and the on-the-fly adaptation such as in the context-specific proportion congruency effect is still under debate, and here we refrain from an extended discussion of this issue.

\section{References}

Abrahamse, E. L., Duthoo, W., Notebaert, W., \& Risko, E. F. (2013). Attention modulation by proportion congruency: The asymmetrical list shifting effect. Journal of Experimental Psychology: Learning, Memory \& Cognition, 39, 1552-1562.

Alain, C., McNeely, H. E., He, Y., Christensen, B. K., \& West, R. (2002). Neurophysiological evidence of error-monitoring deficits in patients with schizophrenia. Cerebral Cortex, 12, 840-846.

Alexander, W. H., \& Brown, J. W. (2011). Medial prefrontal cortex as an action-outcome predictor. Nature Neuroscience, 14, 1338-1344.

Barch, D. M. (2005). The cognitive neuroscience of schizophrenia. Annual Review of Clinical Psychology, 1, 321-353.

Barch, D. M., \& Ceaser, A. (2012). Cognition in schizophrenia: Core psychological \& neural mechanisms. Trends in Cognitive Science, 16, 27-34.

Bates, A. T., Liddle, P. F., Kiehl, K. A., \& Ngan, E. T. (2004). State dependent changes in error monitoring in schizophrenia. Journal of Psychiatric Research, 38, 347-356.

Baving, L., Wagner, M., Cohen, R., \& Rockstroh, B. (2001). Increased semantic \& repetition priming in schizophrenic patients. Journal of Abnormal Psychology, 110, 67-75. 
Becerril, K. E., \& Barch, D. M. (2013). Conflict \& error processing in an extended cingulo-opercular \& cerebellar network in schizophrenia. Neuroimage Clinical, 3, 470-480.

Becerril, K. E., Repovs, G., \& Barch, D. M. (2011). Error processing network dynamics in schizophrenia. Neuroimage, 54, 1495-1505.

Blais, C., Robidoux, S., Risko, E. F., \& Besner, D. (2007). Item-specific adaptation and the conflict monitoring hypothesis: A computational model. Psychological Review, 114, 1076-1086.

Bocanegra, B. R., \& Hommel, B. (2014). When cognitive control is not adaptive. Psychological Science, 25, 1249-1255.

Botvinick, M. M. (2007). Conflict monitoring and decision making: Reconciling two perspectives on anterior cingulate function. Cognitive, Affective, \& Behavioral Neuroscience, 7, 356-366.

Botvinick, M. M., Braver, T. S., Barch, D. M., Carter, C. S., \& Cohen, J. D. (2001). Conflict monitoring \& cognitive control. Psychological Review, 108, 624-652.

Bowie, C. R., \& Harvey, P. D. (2005). Cognition in schizophrenia: Impairments, determinants, \& functional importance. Psychiatric Clinics of North America, 28, 613-633.

Braem, S., Abrahamse, E. L., Duthoo, W., \& Notebaert, W. (2014). What determines the specificity of conflict adaptation? A review, critical analysis, \& proposed synthesis. Frontiers in Psychology, 5; article no. 1134.

Braff, D. L. (1993). Information-processing \& attention dysfunctions in schizophrenia. Schizophrenia Bulletin, 19, 233-259.

Bugg, J. M. (2014). Conflict-triggered top-down control: Default mode, last resort, or no such thing? Journal of Experimental Psychology: Learning, Memory \& Cognition, 40, 567-587.

Bugg, J. M., \& Crump, M. J. C. (2012). In support of a distinction between voluntary and stimulusdriven control: A review of the literature on proportion congruent effects. Frontiers in Psychology: Cognition, 3; article no. 367.

Bugg, J. M., McDaniel, M. A., Scullin, M. K., \& Braver, T. S. (2011). Revealing list-level control in the Stroop task by uncovering its benefits and a cost. Journal of Experimental Psychology: Human Perception and Performance, 37, 1595-1606.

Burglen, F., Marczewski, P., Mitchell, K. J., van der Linden, M., Johnson, M. K., Danion, J. M., \& Salame, P. (2004). Impaired performance in a working memory binding task in patients with schizophrenia. Psychiatry Research, 125, 247-255.

Carter, C. S., MacDonald, A. W., Ross, L. L., \& Stenger, V. A. (2001). Anterior cingulate cortex activity \& impaired self-monitoring of performance in patients with schizophrenia: An eventrelated fMRI study. American Journal of Psychiatry, 158, 1423-1428.

Carter, C. S., Mintun, M., Nichols, T., \& Cohen, J. D. (1997). Anterior cingulate gyrus dysfunction and selective attention deficits in schizophrenia:[15O] H2O PET study during single-trial Stroop task performance. American Journal of Psychiatry, 154, 1670-1675.

Cools, R. (2015). The cost of dopamine for dynamic cognitive control. Current Opinion in Behavioral Sciences, 4, 152-159.

Crump, M. J., \& Milliken, B. (2009). The flexibility of context-specific control: Evidence for contextdriven generalization of item-specific control settings. The Quarterly Journal of Experimental Psychology, 62, 1523-1532.

Dreisbach, G., \& Fischer, R. (2012). The role of affect and reward in the conflict-triggered adjustment of cognitive control. Frontiers in Human Neuroscience, 6; article no. 342.

Dreisbach, G., \& Fischer, R. (2015). Conflicts as aversive signals for control adaptation. Current Directions in Psychological Science, 24, 255-260.

Duthoo, W., Abrahamse, E. L., Braem, S., \& Notebaert, W. (2014). Going, going, gone? Proactive control prevents the congruency sequence effect from rapid decay. Psychological Research, 78 , 483-493.

Duthoo, W., Abrahamse, E. L., Braem, S., Böhler, C. N., \& Notebaert, W. (2014a). The heterogeneous world of congruency sequence effects: An update. Frontiers in Psychology, 5; article no. 1001.

Duthoo, W., Abrahamse, E. L., Braem, S., Böhler, C. N., \& Notebaert, W. (2014b). The congruency sequence effect 3.0: A critical test of conflict adaptation. PLoS ONE, 9, e110462. 
Dutilh, G., Van Ravenzwaaij, D., Nieuwenhuis, S., Van der Maas, H. L. J., Forstmann, B. U., \& Wagenmakers, E.-J. (2012). How to measure post-error slowing: A confound \& a simple solution. Journal of Mathematical Psychology, 56, 208-216.

Egner, T., Ely, S., \& Grinband, J. (2010). Going, going, gone: Characterizing the time-course of congruency sequence effects. Frontiers in Psychology, 1; article no. 154.

Egner, T., \& Hirsch, J. (2005). Cognitive control mechanisms resolve conflict through cortical amplification of task-relevant information. Nature Neuroscience, 8, 1784-1790.

Elliott, R., McKenna, P. J., Robbins, T. W., \& Sahakian, B. J. (1995). Neuropsychological evidence for frontostriatal dysfunction in schizophrenia. Psychological Medicine, 25, 619-630.

Forster, S. E., \& Cho, R. Y. (2014). Context specificity of post-error and post-conflict cognitive control adjustments. PLoS ONE, 9(3), e90281.

Frith, C. D., \& Done, D. J. (1989). Experiences of alien control in schizophrenia reflect a disorder in the central monitoring of action. Psychological Medicine, 19, 359-363.

Fritz, J., \& Dreisbach, G. (2013). Conflicts as aversive signals: Conflict priming increases negative judgments for neutral stimuli. Cognitive, Affective, and Behavioral Neuroscience, 13, 311-317.

Gray, J. A. (1995). Dopamine release in the nucleus-accumbens - the perspective from aberrations of consciousness in schizophrenia. Neuropsychologia, 33, 1143-1153.

Green, M. F., Nuechterlein, K. H., Gold, J. M., Barch, D. M., Cohen, J., Essock, S., ... Marder, S. R. (2004). Approaching a consensus cognitive battery for clinical trials in schizophrenia: The NIMH-MATRICS conference to select cognitive domains \& test criteria. Biological Psychiatry, 56, 301-307.

Grillon, C., Courchesne, E., Ameli, R., Geyer, M. A., \& Braff, D. L. (1990). Increased distractibility in schizophrenic-patients. Electrophysiologic \& behavioral evidence. Archives of General Psychiatry, 47, 171-179.

Henik, A., Carter, C. S., Salo, R., Chaderjian, M., Kraft, L., Nordahl, T. E., \& Robertson, L. C. (2002). Attentional control \& word inhibition in schizophrenia. Psychiatry Research, 110, 137-149.

Holroyd, C. B., \& Coles, M. G. (2002). The neural basis of human error processing: Reinforcement learning, dopamine, \& the error-related negativity. Psychological Review, 109, 679-709.

Hommel, B., Proctor, R. W., \& Vu, K. P. L. (2004). A feature-integration account of sequential effects in the Simon task. Psychological Research, 68, 1-7.

Houthoofd, S., Morrens, M., Sabbe, B., Schrijvers, D., Vandendriessche, F., Hulstijn, W., \& de Bruijn, E. R. A. (2013). Trait \& state aspects of internal \& external performance monitoring in schizophrenia. International Journal of Psychophysiology, 87, 42-51.

Jiang, J., Heller, K., \& Egner, T. (2014). Bayesian modeling of flexible cognitive control. Neuroscience and Biobehavioral Reviews, 46, 30-34.

Jiménez, L., \& Méndez, A. (2013). It is not what you expect: Dissociating conflict adaptation from expectancies in a Stroop task. Journal of Experimental Psychology: Human Perception \& Performance, 31, 271-284.

Jentzsch, I., \& Dudschig, C. (2009). Why do we slow down after an error? Mechanisms underlying the effects of posterror slowing. Quarterly Journal of Experimental Psychology, 62, 209-218.

Kapur, S. (2003). Psychosis as a state of aberrant salience: A framework linking biology, phenomenology, \& pharmacology in schizophrenia. American Journal of Psychiatry, 160, 13-23.

Kerns, J. G., Cohen, J. D., MacDonald, A. W., Johnson, M. K., Stenger, V. A., Aizenstein, H., \& Carter, C. S. (2005). Decreased conflict- \& error-related activity in the anterior cingulate cortex in subjects with schizophrenia. Americam Journal of Psychiatry, 162, 1833-1839.

Kim, S., \& Cho, Y. S. (2014). Congruency sequence effect without feature integration \& contingency learning. Acta Psychologica, 149, 60-68.

Kool, W., McGuire, J. T., Rosen, Z. B., \& Botvinick, M. M. (2010). Decision making \& the avoidance of cognitive demand. Journal of Experimental Psychology: General, 139, 665-682.

Laurens, K. R., Ngan, E. T., Bates, A. T., Kiehl, K. A., \& Liddle, P. F. (2003). Rostral anterior cingulate cortex dysfunction during error processing in schizophrenia. Brain, 126, 610-622.

Lesh, T. A., Niendam, T. A., Minzenberg, M. J., \& Carter, C. S. (2011). Cognitive control deficits in schizophrenia: Mechanisms \& meaning. Neuropsychopharmacology, 36, 316-338. 
Lesh, T. A., Westphal, A. J., Niendam, T. A., Yoon, J. H., Minzenberg, M. J., Ragland, J. D., ... Carter, C. S. (2013). Proactive \& reactive cognitive control \& dorsolateral prefrontal cortex dysfunction in first episode schizophrenia. Neuroimage: Clinical, 2, 590-599.

Mathalon, D. H., Fedor, M., Faustman, W. O., Gray, M., Askari, N., \& Ford, J. M. (2002). Responsemonitoring dysfunction in schizophrenia: An event-related brain potential study. Journal of Abnormal Psychology, 111, 22-41.

Mayr, U. (2004). Conflict, consciousness, \& control. Trends in Cognitive Science, 8, 145-148.

McNeely, H. E., West, R., Christensen, B. K., \& Alain, C. (2003). Neurophysiological evidence for disturbances of conflict processing in patients with schizophrenia. Journal of Abnormal Psychology, 112, 679-688.

Minzenberg, M. J., Gomes, G. C., Yoon, J. H., Swaab, T. Y., \& Carter, C. S. (2014). Disrupted action monitoring in recent-onset psychosis patients with schizophrenia \& bipolar disorder. Psychiatry Research, 221, 112-121.

Mordkoff, J. T. (2012). Observation: Three reasons to avoid having half of the trials be congruent in a four-alternative forced-choice experiment on sequential modulation. Psychonomic Bulletin \& Review, 19, 750-757.

Morrens, M., Hulstijn, W., Lewi, P., \& Sabbe, B. (2008). Bleuler revisited: Psychomotor slowing in schizophrenia as part of a catatonic symptom cluster. Psychiatry Research, 161, 121-125.

Morrens, M., Hulstijn, W., \& Sabbe, B. (2007). Psychomotor slowing in schizophrenia. Schizophrenia Bulletin, 33, 1038-1053.

Notebaert, W., Houtman, F., van Opstal, F., Gevers, W., Fias, W., \& Verguts, T. (2009). Post-error slowing: An orienting account. Cognition, 111, 275-279.

Núñez Castellar, E., Houtman, F., Gevers, W., Morrens, M., Vermeylen, S., Sabbe, F., \& Notebaert, W. (2012). Increased orienting to unexpected action outcomes in schizophrenia. Frontiers in Human Neuroscience, 6; article no. 32.

O'Driscoll, C., Laing, J., \& Mason, O. (2014). Cognitive emotion regulation strategies, alexithymia and dissociation in schizophrenia, a review and meta-analysis. Clinical Psychology Review, 34, 482-495.

Perez, V. B., Ford, J. M., Roach, B. J., Woods, S. W., McGlashan, T. H., Srihari, V., ... Mathalon, D. H. (2012). Error monitoring dysfunction across the illness course of schizophrenia. Journal of Abnormal Psychology, 121, 372-387.

Polli, F. E., Barton, J. J., Thakkar, K. N., Greve, D. N., Goff, D. C., Rauch, S. L., \& Manoach, D. S. (2008). Reduced error-related activation in two anterior cingulate circuits is related to impaired performance in schizophrenia. Brain, 131, 971-986.

Polli, F. E., Barton, J. J., Vangel, M., Goff, D. C., Iguchi, L., \& Manoach, D. S. (2006). Schizophrenia patients show intact immediate error-related performance adjustments on an antisaccade task. Schizophrenia Research, 82, 191-201.

Scherbaum, S., Fischer, R., Dshemuchadse, M., \& Goschke, T. (2011). The dynamics of cognitive control: Evidence for within-trial conflict adaptation from frequency-tagged EEG. Psychophysiology, 48, 591-600.

Schmidt, J. R. (2013). Questioning conflict adaptation: Proportion congruent \& Gratton effects reconsidered. Psychonomic Bulletin \& Review, 20, 615-630.

Schmidt, J. R., \& Besner, D. (2008). The Stroop effect: Why proportion congruent has nothing to do with congruency \& everything to do with contingency. Journal of Experimental Psychology: Learning, Memory \& Cognition, 34, 514-523.

Schmidt, J. R., \& De Houwer, J. (2011). Now you see it, now you don't: Controlling for contingencies \& stimulus repetitions eliminates the Gratton effect. Acta Psychologica, 138, 176-186.

Schmidt, J. R., \& Weissman, D. H. (2014). Congruency sequence effects without feature integration or contingency learning confounds. PLoS ONE, 9, e102337.

Schouppe, N., Braem, S., De Houwer, J., Silvetti, M., Verguts, T., Ridderinkhof, K. R., \& Notebaert, W. (2015). No pain, no gain: The affective valence of congruency conditions changes following a successful response. Cognitive, Affective, \& Behavioral Neuroscience, 15, 251-261. 
Schouppe, N., De Houwer, J., Ridderinkhof, K. R., \& Notebaert, W. (2012). Conflict: Run! Reduced Stroop interference with avoidance responses. Quarterly Journal of Experimental Psychology, 65, 1052-1058.

Shenhav, A., Botvinick, M. M., \& Cohen, J. D. (2013). The expected value of control: An integrative theory of anterior cingulate cortex function. Neuron, 79, 217-240.

Silvetti, M., Seurinck, R., \& Verguts, T. (2011). Value \& prediction error in medial frontal Cortex: Integrating the single-unit \& systems levels of analysis. Frontiers in Human Neuroscience, 5; article no. 75.

Tzelgov, J., Henik, A., \& Berger, J. (1992). Controlling Stroop effect by manipulating expectation for color related stimuli. Memory \& Cognition, 20, 727-735.

Verguts, T., \& Notebaert, W. (2009). Adaptation by binding: A learning account of cognitive control. Trends in Cognitive Sciences, 13, 252-257.

Verguts, T., Notebaert, W., Kunde, W., \& Wühr, P. (2011). Post-conflict slowing: Cognitive adaptation after conflict processing. Psychonomic Bulletin \& Review, 18, 76-82.

Verguts, T., Vassena, E., \& Silvetti, M. (2015). Adaptive effort investment in cognitive and physical tasks: A neurocomputational model. Frontiers in Behavioral Neuroscience, 9; article no. 57.

Völter, C., Strobach, T., Aicher, D. S., Wöstmann, N., Costa, A., ... Ettinger, U. (2012). Schizotypy \& behavioural adjustment \& the role of neuroticism. PLoS ONE, 7, e30078.

Weissman, D. H., Jiang, H., \& Egner, T. (2014). Determinants of congruency sequence effects without learning \& memory confounds. Journal of Experimental Psychology: Human Perception \& Performance, 40, 2022-2037.

Westerhausen, R., Kompus, K., \& Hugdahl, K. (2011). Impaired cognitive inhibition in schizophrenia: A meta-analysis of the Stroop interference effect. Schizophrenia Research, 133, 172-181.

Westerhausen, R., Kompus, K., \& Hugdahl, K. (2013). Unaffected control of distractor interference in schizophrenia: A meta-analysis of incompatibility slowing in flanker tasks. Journal of Psychiatric Research, 47, 246-251. 